East African Medical Journal Vol. 86 No. 7 July 2009

PSYCHOSOCIAL ASPECTS OF BREAST CANCER TREATMENT IN ACCRA, GHANA

J. N. A. Clegg-Lamptey MBChB, FRCS, FWACS, FGCS, CBASenior Lecturer, Department of Surgery, University of Ghana Medical School, P. O. Box 4236, Accra, Ghana, J. C. B. Dakubo, BSc, MBChB, FWACS, Surgical Specialist and Y. N. Attobra, RGN, Senior Staff Nurse, Department of Surgery, Korle Bu Teaching Hospital, P. O. Box KB77, Accra, Ghana

Request for reprints to: Mr. J. N. A. Clegg-Lamptey, Department of Surgery, University of Ghana Medical School, P. O. Box 4236, Accra, Ghana

\title{
PSYCHOSOCIAL ASPECTS OF BREAST CANCER TREATMENT IN ACCRA, GHANA
}

\author{
J. N. A. CLEGG-LAMPTEY, J. C. B. DAKUBO and Y. N. ATTOBRA
}

\begin{abstract}
Objectives: To evaluate psychosocial influences and effects of breast cancer treatment.

Design: Cohort questionnaire survey.

Setting: Surgical Outpatient Department, Korle Bu Teaching Hospital (KBTH), Accra, Ghana.

Subjects: Women previously treated for breast cancer, including those still on hormonal therapy.

Main outcome measures: Perception of quality of treatment and psychosocial support; and patients' felt needs for alternative treatment.

Results: Eighty nine women treated one to 22 years previously were interviewed. The majority $(86 \%)$ had mastectomy. Chemotherapy was the most unpleasant aspect of treatment in $58(65.2 \%)$, and $27(30.3 \%)$ were not warned about complications of treatment. Thirty eight $(42.7 \%)$ reported being afraid (frightened or terrified) at the diagnosis; other reactions were shock, devastation, weeping and depression. Twenty two $(24.7 \%)$ received no counselling and $15(18.5 \%)$ did not have opportunity to express their fears of death $55(61.8 \%)$, mastectomy/deformity $27(30.3 \%)$ and financial incapability $23(25.8 \%)$. Forty four $(49.4 \%)$ used alternate 'treatment', mainly prayer camps ( 25 cases) and herbs ( 22 cases), before and during hospital treatment. Use of alternate treatment led to delays in treatment in 23 women. They had complaints about the care they received: lack of sympathy and emotional support (16 cases), lack of information and communication (13 cases), lack of counselling (9 cases) and slow processes (8 cases).

Conclusions: Many patients utilise prayer camps and herbs leading to delays in treatment. Breast cancer patients in Ghana (West Africa) are not receiving satisfactory emotional support, communication and counseling. Adequate psychosocial interventions need to be implemented.
\end{abstract}

\section{INTRODUCTION}

Breast cancer is no longer an uncommon disease in developing countries. Cancer is the third commonest cause of hospital admissions in Ghana, after cardiovascular diseases and accidents / poisons (1); and breast cancer is the most common cancer in the country, accounting for $16 \%$ of all cancers documented at the Pathology Department of the Korle Bu Teaching Hospital (KBTH) (2).

Breast cancer has been shown to be associated with psychosocial problems and these may have an effect on prognosis (3). Patients with breast cancer go through severe emotional problems that may be related to their socioeconomic situation, psychological make-up and coping abilities, the medical parameters of the disease, the type of operation they undergo (mastectomy or lumpectomy), other forms of adjuvant treatment (chemotherapy, hormonal therapy or radiotherapy), the side effects of the treatment, and the availability of emotional and financial support (3-5).

In Ghana, as in many other countries, there is stigma and many misconceptions about the cause, treatment, outcome and other effects of the disease. These result in severe emotional trauma for patients 
and probably contribute to delayed presentation: 60$70 \%$ of breast cancers in Ghana report at an advanced stage (6).

Most patients with breast complaints are seen at the general surgical outpatient clinics at the KBTH where the diagnosis of breast cancer is made after triple assessment. The clinics are busy, as the surgeons see cases with no appointment system in place. With medical students to be taught and emergencies to be attended to, patients are often given only a few minutes of the surgeon's time. There is little time to engage in prolonged counselling.

Breast cancer, being a heterogeneous disease, does not have one standard treatment; the treatment is customised to each patient and their tumour characteristics $(7,8)$. The patients, therefore, sometimes have to be engaged in considering a range of options. They go through many investigations and see different specialists: surgeons, radiologists, and medical and radiation oncologists. They also have to attend anaesthetic clinics before surgery. Treatment takes many months or years and is often associated with complications. Patients are therefore necessarily bombarded with information about diagnosis, investigations and various modes of treatment. They sometimes have to consider treatment options and understand the implications and possible complications to the various treatments. It takes a long time for anyone to digest such information especially when it is associated with such emotional trauma, financial considerations and stigma that breast cancer patients have to contend with.

The cultural practices and other beliefs of Ghanaians sometimes add another dimension to the problem: because most of our patients prefer to let the doctor decide what is best for them and would rather have no input themselves, many patients end up with little information about the complexities of breast cancer treatment. Doctors who getaccustomed to deciding for patients sometimes make the mistake of not giving breast cancer patients adequate information and explanation.

This study sought to assess the experiences and impressions of breast cancer survivors with regard to treatment obtained at the KBTH. The results of the study should help medical staff treating breast cancer patients from our socio-cultural background modify aspects of their care, and thus offer improved quality of care.

\section{MATERIALS AND METHODS}

A questionnaire survey was carried out among women survivors who had completed breast cancer treatment and were attending follow-up clinics at the KBTH, after prior permission from hospital authorities. Questions were asked about types of treatment, counselling received and how they financed their treatment. They were asked about whether they were informed about complications of treatment. We also sought information about other (non-hospital treatment) they had sought and if that delayed any part of their hospital treatment.

Other questions dealt with the fears and anxieties they had at the time of diagnosis and whether they had opportunities to express those fears. Finally they were asked about what they did not like about hospital treatment and their suggestions for improved quality of care for breast cancer patients.

The questionnaires were administered by two nurses and two medical students on a mentorship programme.

\section{RESULTS}

There were 89 women interviewed, aged between 28 and 86 (mean 53.7, SD 11.7) years. Sixty three (70.8\%) were married, seven $(7.9 \%)$ were single, seven $(7.9 \%)$ were divorced or separated and 12(13.5\%) were widows. Most of them were active workers: 14 of the $27(30.3 \%)$ self-employed were traders. Others 17 $(19.1 \%)$ were in the hospitality industry, $14(15.7 \%)$ professionals, eight $(8.9 \%)$ office workers and six $(6.74 \%)$ housewives. Fourteen $(15.7 \%)$ were retired and only three (3.4\%) said they were unemployed. At the time they were diagnosed with breast cancer 54 $(60.7 \%)$ did not know of any breast cancer survivor. They knew it as a fatal disease.

Educational status: Ten (11.2\%) of those interviewed had no formal education, 17 (19.1\%) had primary education, $39(43.8 \%)$ had secondary education and $23(25.8 \%)$ had tertiary education.

Treatment received: The patients were breast cancer survivors for periods that ranged from one year to 22 years (mean 3.5 years). They had all completed their initial treatment, except those on hormonal (oral) treatment.

Table 1 shows the treatments that patients had. No one in this series had received Trastuzumab immunotherapy. Chemotherapy was the most unpleasant part of the treatment for $58(65.2 \%)$, surgery for seven $(7.9 \%)$, radiotherapy for seven $(7.9 \%)$, the frequent hospital visits for three (3.4\%) and hormonal therapy for one $(1.1 \%)$. Nine $(19.1 \%)$ found every aspect of the treatment unpleasant, and four (4.5\%) did not find any part of the treatment unpleasant. Sixty two $(69.7 \%)$ were warned about the complications of treatment but $27(30.3 \%)$ were not. 
Table 1

Treatment received by patients

\begin{tabular}{lll}
\hline Treatment & No. & $(\%)$ \\
\hline Mastectomy & 78 & 87.6 \\
Bilateral mastectomy & 1 & 1.1 \\
Lumpectomy & 10 & 11.2 \\
Chemotherapy & 85 & 95.5 \\
Radiotherapy & 43 & 48.3 \\
Hormonal therapy & 43 & 48.3 \\
Capecitabine & 3 & 3.4 \\
\hline
\end{tabular}

Reaction to diagnosis: Patients were informed about their diagnosis by the attending doctor in the consulting room. Their reaction to the news is summarised in their own words (Table 2). Sixty seven $(75.3 \%)$ had received some counselling, but 22(24.7\%) had no counselling at all.

Table 2

Patients' reaction to diagnosis

\begin{tabular}{lll}
\hline $\begin{array}{l}\text { Reaction to } \\
\text { diagnosis }\end{array}$ & No. & $(\%)$ \\
\hline Afraid, Terrified & 38 & 42.7 \\
Shock & 20 & 22.5 \\
Devastated & 10 & 11.2 \\
Wept & 9 & 10.1 \\
Depressed & 6 & 6.7 \\
Disbelief & 5 & 5.6 \\
Sad & 5 & 5.6 \\
Lost appetite & 4 & 4.5 \\
Insomnia & 3 & 3.4 \\
Suicidal & 1 & 1.1 \\
Nil, Indifference & 10 & 11.2 \\
\hline
\end{tabular}

Patients' fears: The fears patients had after being informed of their diagnosis is summarised in Table 3. Not surprisingly the leading fears were the fear of death and mastectomy. Of the 81 who had fears, $66(81.5 \%)$ had opportunity to express their fears, but $15(18.5 \%)$ had none.
Table 3

Patients' fears

\begin{tabular}{lll}
\hline Fears & No. & $(\%)$ \\
\hline Death & 55 & 61.8 \\
Mastectomy, Deformity & 27 & 30.3 \\
Cost of treatment & 23 & 25.8 \\
Uncertain future & 9 & 10.1 \\
Job security & 7 & 7.9 \\
Marriage security & 5 & 5.6 \\
Stigmatisation & 5 & 5.6 \\
Hospitalisation & 5 & 5.6 \\
Alopecia & 4 & 4.5 \\
Pain & 3 & 3.4 \\
Others & 2 & 2.2 \\
No fears & 8 & 9.0 \\
\hline
\end{tabular}

Non-hospital treatment: Forty four patients (49.4\%) made use of alternate non-hospital 'treatment' in an attempt to achieve cure of their cancer. Twenty three of them $(52.3 \%)$ admitted that it led to delays in their treatment. The non-hospital means they resorted to were prayers and prayer camps by 25 out of $44(56.8 \%)$, herbs by $22(50 \%)$, organic foods and food supplements by seven (15.9\%), Chinese remedies in two $(4.5 \%)$ and homeopathy in two $(4.5 \%)$. Fifteen of them used more than one remedy. Of the 44 patients that used non-hospital treatment, $21(47.7 \%)$ did so before they started hospital treatment. Six (13.6\%) used them during hospital treatment, and five $(11.4 \%)$ after their treatment. Four $(9.1 \%)$ used non-hospital treatment before and during hospital treatment; eight (18.2\%) before, during and after hospital treatment.

Financing treatment: Many patients used their own resources but needed much help. Their sources of finance (Table 4) reveal their reliance on family and religious networks. 
Table 4

Sources of finance

\begin{tabular}{lll}
\hline Source & No. & $(\%)$ \\
\hline Patient's resources & 62 & 68.7 \\
Relatives & 47 & 52.8 \\
Spouse & 28 & 31.5 \\
Church/Mosque & 17 & 19.1 \\
Employer & 16 & 18 \\
Friends & 11 & 12.4 \\
Sold property & 4 & 4.5 \\
Savings and & & \\
Investments & 3 & 3.4 \\
Children & 3 & 3.4 \\
Social clubs & 2 & 2.2 \\
Appeal for funds & 1 & 1.1 \\
\hline
\end{tabular}

Areas of dissatisfaction: Sixty one of the 89 women were dissatisfied with their treatment. The complaints are listed in Table 5.

Table 5

Areas of patients' dissatisfaction

\begin{tabular}{lr}
\hline Complaint & No. \\
\hline Lack of sympathy and emotional support & 16 \\
Lack of information and communication & 13 \\
Lack of counselling & 9 \\
Processes too slow & 8 \\
Long wait for histology report & 6 \\
Lack of financial support & 2 \\
Little involvement of patient in Rx decisions & 2 \\
Others & 5 \\
\hline Total & 61 \\
\hline
\end{tabular}

\section{DISCUSSION}

This group of survivors reveal women actively engaged in various occupations. Most of the illiterates were involved in trading activities and were bread winners of their families. It is known that, compared to Caucasians, women of African descent develop breast cancer at a younger age (6-9), when they are likely to be actively engaged in income generation.

There is stigma attached to having breast cancer in Ghana as in many other countries. Healthy individuals assign stigma and avoidance behaviour is directed at cancer patients (10). Because of thisstigma, many patients keep the diagnosis to themselves. It is therefore not surprising that $60 \%$ of our women did not know of anyone who had survived breast cancer at the time of their diagnosis. This fuels the impression that breast cancer cannot be cured.

The number of patients who had mastectomy is high compared to what pertains in more developed countries. This can be partly explained by the advanced nature of tumours in our country. It also explains why as many as $95 \%$ of our patients had chemotherapy, although only $41 \%$ of breast cancers in Ghana show hormone receptor positivity (11). It is good to note that few patients in Ghana (48\%) now receive hormonal therapy, perhaps an indication that most patients now have their hormone receptor status determined before treatment. This is a positive change from what was obtained a few years ago, when there were very few facilities for hormone receptor status determination, and all patients were prescribed Tamoxifen blindly (12).

A combination of factors - stigma of breast cancer, the fact that it is considered fatal, and the fears and misconceptions associated with the disease - is likely to generate a lot of anxiety and fear in patients when they are informed about the diagnosis of breast cancer. In other reports, breast cancer patients go through emotions of denial, feeling of injustice, guilt, failure, betrayal, bewilderment, powerlessness, isolation and doom $(13,14)$. The main reactions of our patients to their diagnosis were fear (terror), shock, devastation, weeping and depression. These patients feel vulnerable. Their cultural beliefs might address their state of vulnerability leading to them turning to traditional healers (13). In this study about half of the patients used non-hospital 'treatment', mainly herbs and prayer camps. This large number of patients going to prayer camps and resorting to the use of herbs reflects patients' beliefs, but also shows that we have failed to address their state of vulnerability. Our patients therefore need more counselling and tender loving care. In this study, however, many patients were not offered counselling at all. This needs to change.

The financial burden in breast cancer treatment is great and many patients cannot afford treatment. Efforts should be made by our health authorities to further subsidise the cost of the various treatments. Main fears expressed by the women were: fear 
of death (62\% of women), fear of mastectomy and associated deformity (30\%), and the inability to finance treatment (26\%). The authors have constantly been confronted with a very common misconception in Ghana: that women who undergo mastectomy will die within a couple of years. This belief probably explains why the fear of death and mastectomy are the main fears that patients have. These fears may also explain why many patients with breast cancer in Ghana delay reporting to hospital for many months, abscond during neoadjuvant therapy when surgery is due (6), and resort to other therapies. Their aim appears to avoid surgery at all cost.

Patients should have the opportunity to express their fears, especially since it appears their fears affect how they avail themselves of hospital treatment. Unfortunately, as shown in this study, many of the patients were not given the opportunity to express their fears.

Many of the survivors $(67 \%)$ had some dissatisfaction with the treatment they received. The suggestions they make need to be taken seriously. Incidentally it reflects the deficiencies already identified. The first area they identified was a lack of sympathy and emotional support. The second and third are about lack of information and communication, and inadequate counselling. These three account for $62 \%$ of the concerns raised.

In developed countries there is a lot of information available to women with breast cancer and it is men with breast cancer who might find that information is insufficient and inappropriate (15). Our women with breast cancer are not receiving enough information. Our men with breast cancer face a worse predicament.

How can the problem of inadequate counselling, communication and giving information to patients be addressed? Much time needs to be spent with these patients. This is often not possible in the busy out-patients' clinic. The use of clinical psychologists, breast care nurses and breast survivor volunteers should be considered as part of the management of our breast cancer patients, as happens in more advanced countries. Other home-made interventions have to be considered to address the peculiar problems identified, like the resort to herbal treatment and prayer camps that lead to delayed treatment and absconding. Those of our patients who are literate or have literate friends and relatives should be given information leaflets about breast cancer and its treatment. They should also be given the telephone numbers of cancer support organisations and that of a contact person in case they have questions, difficulties, or are in need of clarification or encouragement.

The availability of psychosocial interventions, including emotional and financial support, have been found to be important in the psychological impact and emotional responses of breast cancer patients $(3,16)$. From this study, these appear to be deficient in our practice. This preliminary study should serve as a basis of a more extensive study to determine the extent to which our patients with breast cancer are affected by the quality of care they receive, especially as regards emotional support, communication and counselling.

\section{ACKNOWLEDGEMENTS}

The authors are grateful to the following for carrying out patient interviews:I.Darko (staff nurse), R. Glover and C. Kwakofi (medical students on mentorship programme). We are also grateful to the women who answered our questions and have enabled us draw conclusions to help future breast cancer sufferers.

\section{REFERENCES}

1. Biritwum, R. B., Gulaid, J. and Amaning, A.O. Pattern of diseases or conditions leading to hospitalisation at the Korle Bu Teaching Hospital. Ghana. Med. J. 2000; 34:197-205.

2. Clegg-Lamptey, J.N., Baako, B.N. and Badoe, E.A. The Breast. In: Badoe E.A., Archampong E.Q. and da Rocha-Afodu J.T. (editors) Principles and Practice of Surgery including Pathology in the Tropics, 4th Edition. Accra: Department of Surgery. University of Ghana Medical School. 2009; 488-519.

3. Payne, D.K., Sullivan, M.D. and Massie, M.J. Women's psychological reactions to breast cancer. Semin Oncol. 1996; 23(1 Supp12):89-97.

4. Adachi, K., Ueno, T., Fujioka, T., Fujitomi, Y. and Uco, H. Psychosocial factors affecting the therapeutic decision-making and postoperative mood states in Japanese breast cancer patients who underwent various types of surgery: Body image and sexuality. Jpn. J. Clin. Onco. 2007;37:412-418.

5. Hislop, T.G., Waxler, N.E., Coldman, A.J. et al. The prognostic significance of psychosocial factors in women with breast cancer. J. Chronic. Dis. 1987; 40: 729-735.

6. Clegg-Lamptey, J.N.A. and Hodasi, W. M. A study of breast cancer in Korle Bu Teaching Hospital: assessing the impact of health education. Ghana Med. J. 2007; 41: 72-77.

7. Petrelli, F., Cabiddu, M., Cazzaniga, M. E. et al. Targeted therapies for the treatment of breast cancer in the post-trastuzumab era. Oncologist. 2008; 13:373381.

8. Bullock, K. and Blackwell, K. Clinical efficacy of taxane-trastuzumab combination regimens for HER- 
2-positive metastatic breast cancer. Oncologist. 2008 13: $515-525$

9. Fregene, A. and Newman L.A. Breast cancer in subSaharan Africa: how does it relate to breast cancer in African-American women? Cancer. 2005; 103: 15401550.

10. Peters-Golden, H. Breast cancer: varied perceptions of social support in the illness experience. Soc. Sci. Med. 1982;16:483-491.

11. Varney, J., Vanderpuye, V. and Clegg-Lamptey, J.N.A. Hormone receptor and Her- 2 expression in breast cancers among sub-Saharan African women. Breast. J. 2008; 14: 510-511.

12. Baako, B. N. and Badoe, E.A. Treatment of breast cancer in Accra: 5-year survival. Ghana. Med. J. 2001: 35: 90-93.
13. Kaur, R. Personal account-breast cancer. Lancet. 2005; 365: 1742.

14. Colyer, H. Women's experience of living with cancer. I. Adv. Nurs. 1996; 23: 496-501.

15. Iredale, R., Brain, K., Williams, B. et als. Theexperiences of men with breast cancer in the United Kingdom. Eur. J. Cancer. 2006; 42: 334- 341.

16. Ohaeri, J.U., Campbell, O.B., Ilesanmil, A.O. and Ohaeri, B.M. Psychosocial concerns of Nigerian women with breast and cervical cancer. Psychooncology. 1998; 7: 494-501. 